This document is confidential and is proprietary to the American Chemical Society and its authors. Do not copy or disclose without written permission. If you have received this item in error, notify the sender and delete all copies.

\title{
Tuning Charge Transport Properties of Asymmetric Molecular Junctions
}

\begin{tabular}{|r|l|}
\hline Journal: & The Journal of Physical Chemistry \\
\hline Manuscript ID & jp-2017-01105v.R1 \\
\hline Manuscript Type: & Article \\
\hline Date Submitted by the Author: & $26-$ May-2017 \\
\hline Complete List of Authors: & $\begin{array}{l}\text { Sebera, Jakub; Institute of Organic Chemistry and Biochemistry AS CR, } \\
\text { V.v.i., Molecular Spectroscopy } \\
\text { Kolivoska, Viliam; J. Heyrovsky Institute of Physical Chemistry, ASCR, } \\
\text { Valášek, Michal; Karlsruhe Institute of Technology (KIT), Institute of } \\
\text { Nanotechnology (INT) } \\
\text { Gasior, Jindřich; J. Heyrovsky Institute of Physical Chemistry } \\
\text { Sokolova, Romana; J. Heyrovsky Institute of Physical Chemistry of ASCR, } \\
\text { V.v.i., Molecular electrochemistry } \\
\text { Meszaros, Gabor; Hungarian Academy of Sciences, Research Centre for } \\
\text { Natural Sciences, Institute of Materials and Environmental Chemistry } \\
\text { Hong, Wenjing; Xiamen University } \\
\text { Mayor, Marcel; University of Basel, Department of Chemistry } \\
\text { Hromadova, Magdalena; J. Heyrovsky Institute of Physical Chemistry }\end{array}$ \\
\hline
\end{tabular}

\section{SCHOLARONE}

Manuscripts 


\section{INTRODUCTION}

Single molecule junction formed by trapping an individual molecule between two electrodes represents a unique experimental platform for studies of the relationship between the molecular conductance and molecular structure. Several properties of molecules like their length, ${ }^{1-4}$ conformation, ${ }^{5-9}$ conjugation ${ }^{10}$ or charge localization ${ }^{11,12}$ and the type of the anchoring groups ${ }^{13,14}$ have been explored. Recently, the conductance properties of the intermolecular junctions including two molecules interacting non-covalently through $\pi-\pi$ coupling, ${ }^{15,16}$ hydrogen bonding, host-guest ${ }^{17}$ and coordination complex $^{18}$ formation have been addressed.

Several multipodal platforms have been scrutinized for their possible use in molecular electronics. ${ }^{19-27}$ Flat triazatriangulene ring system (TATA) was used as anchoring platform for (oligo)phenylene wires of different length. Electrical conductance of the self-assembled monolayers (SAMs) of these molecules was compared to conductance of SAMs composed of thiol-terminated (oligo)phenylene wires. Authors showed that contact resistance of TATA platform is only slightly bigger compared to thiol anchoring group demonstrating its suitability for development of molecular electronic devices. ${ }^{19}$ Hammerich et al. ${ }^{20}$ showed that SAMs composed of the imine-functionalized TATA platform were able to under- go trans-cis isomerization upon irradiation with fast thermal switching back to trans isomer.

Ie et al. presented new tripodal anchor composed of a tetraphenylmethane core with three selenol arms as an alternative to thiol terminated molecules and demonstrated the formation of compact monolayers on the gold surface. ${ }^{21}$ Charge transport was studied recently in pyridine and thiophene terminated tetraphenylmethane tripods. Tested molecules were symmetric and contained two tetraphenylmethane tripods sharing a common phenylene. Thermopower measurements confirmed that the hole transport is operative in the molecules with thiophene anchoring groups, whereas electron transport prevails in the case of pyridine anchors. The conductance of bis-tripodal molecule with thiophene termini was reported to be $2 \times 10^{-5} \mathrm{G}_{0}$. The versatility of $\pi$-channel anchors for the control of the charge carrier type has been demonstrated. ${ }^{22}$ Molecular junction (MJ) containing symmetric molecule made from two tris-pyridine terminated tetraphenylmethane tripods connected through an ethynylene spacer gave conductance value $(5 \pm 1) \times 10^{-4} \mathrm{G}_{0}$, which represents two orders of magnitude higher single molecule conductance compared to the symmetric pyridine terminated phenylene ethynylene reference molecule. ${ }^{23}$ Lindner et al. studied the effect of the position of thiol anchoring groups (para versus meta) attached to the tetraphenylmethane plat- 
form on the SAM formation. ${ }^{25}$ Authors concluded that meta substitution yields well-ordered monolayers with all three legs anchored to the gold substrate, whereas a multilayer formation was obtained for para derivative. The position of anchoring groups did not affect significantly the single molecule conductance values of these molecules and in both cases it was around $9 \times 10^{-5} \mathrm{G}_{0}$. It should be stressed that platforms based on the tetraphenylmethane core contain an $\mathrm{sp}^{3}$ carbon, which should impact their charge transport properties. This is indeed reflected in the experimentally obtained single molecule conductance values.

In the present work we explore the conductance properties of a new type of 9,9'-spirobifluorene tripodal platform which allows for the conjugated charge transport path along one of the fluorene units. ${ }^{26,27}$ Such tripod was introduced recently to provide efficient charge transport to the metal surface and to control spatial arrangement of molecular wires with respect to the surface. ${ }^{26}$ The platform showed promising charge transport properties at $4 \mathrm{~K}$ giving a relatively high conductance of the order of $10^{-3} \mathrm{G}_{0}$. Based on the combined experimental and theoretical investigation of elastic and inelastic charge transport the conductance along the conjugated part of the molecule was confirmed. ${ }^{27}$

In this paper we address the possibility to manipulate the charge transport path in the highly asymmetric molecules containing this tripodal platform. By making multiple contacts to the electrode the anchor can also promote a decrease in the number of possible configurations of the molecule within the junction at room temperature, which is important parameter in view of the practical use of the molecular electronic devices.

\section{EXPERIMENTAL SECTION}

Material. Argon gas (Messer, 99.998 \% purity), sodium hydroxide (99.99\%, Alfa Aesar), 1,3,5-trimethylbenzene (mesitylene, 98\% Sigma Aldrich), triethylamine (99.5\% Bioultra, Sigma Aldrich), decane (>99.9\%, anhydrous, Sigma Aldrich), nitric acid (65\% p.a. Lach-Ner, Czech Republic), sulfuric acid (96\%, p.a. Lach-Ner, Czech Republic and Suprapur, Merck), hydrogen peroxide (30 \%, p.a. Lach-Ner, Czech Republic) and absolute ethanol (99.8\%, molecular biology grade, AppliChem $\mathrm{GmbH}$, Darmstadt, Germany and p.a. Penta, Czech Republic) were used as received. Ultrapure deionized water with a minimum resistivity of $18.2 \mathrm{M} \Omega \cdot \mathrm{cm}$ and TOC of $3 \mathrm{ppb}$ was obtained by means of a Milli-Q Integral 5 water purification system (Merck Millipore, France). All glassware, Kalrez O-rings, PTFE and Kel-F liquid cell parts were cleaned in boiling 30\% nitric acid, which was followed by repeated boiling in ultrapure water and drying at $105^{\circ} \mathrm{C}$. Molecules $\mathbf{1}$ to $\mathbf{5}$ (Chart 1) were prepared as thioacetates and their deprotection to corresponding thiols was achieved in-situ by triethylamine solution (10\%) in the mesitylene solvent. Synthesis of molecule 5 is given in Section 1 of the Supporting Information (SI). Synthesis of compounds $\mathbf{1}$ to $\mathbf{4}$ is described in detail elsewhere. ${ }^{26,27}$

Scanning Tunneling Microscopy Break Junction (STMBJ) Measurements. Detailed description of an in-house implemented STMBJ setup is given in the Section 2 of the SI. Measurements were done at suspended z-piezo drive voltage feedback control and at the bias voltage set to $130 \mathrm{mV}$ between the gold tip and the gold substrate. Setup enables continuous collection of the approach and retraction curves with $\mathrm{z}$-piezo drive voltage and junction current being monitored as a function of time. Typically 4000 junction cycles were collected to obtain statistically significant amount of data. Only the retraction curves were extracted from collected data sets for further analysis. Dependence of the tip current on the $\mathrm{z}$-axis piezo drive voltage was converted into the conductance-distance curves using the actual calibration constants for piezo and electronic elements used. Extraction of the retraction curves, their conversion to conductance-distance curves and construction of the corresponding histograms was done using a combination of the in-house developed software (Delphi programming environment, RAD Studio, Embarcadero, USA) and OriginPro 9.1 (OriginLab Corporation, USA). Bin size of 0.005 was used for the construction of $1 \mathrm{D}$ histograms of $\log \left(\mathrm{G} / \mathrm{G}_{0}\right)$ values, where $\mathrm{G}$ is the conductance presented in the units of the quantum conductance $\mathrm{G}_{0}=77.5 \mu \mathrm{S}$. For the construction of $2 \mathrm{D}$ histograms the bin size values of 0.05 for $\log \left(\mathrm{G} / \mathrm{G}_{0}\right)$ and $0.02 \mathrm{~nm}$ for $\Delta \mathrm{z}$ distance values were used. The gold tip electrodes were prepared from $0.25 \mathrm{~mm}$ electrochemically etched gold wire. ${ }^{28}$

Mechanically Controllable Break Junction (MCBJ) measurements. The MCBJ technique may be viewed as complementary to the STMBJ approach. Its chief advantage over the latter is a wider dynamic range of the electric current, which allows investigation of the molecular junctions in later stages of their evolution. A drawback of the MCBJ technique is related to the uncertainty of the distance estimation between two electrodes. Detailed description of an in-house implemented MCBJ setup is given in the Section 2 of the SI. The junction opening/closing cycle was typically repeated 3000 times to obtain statistically significant amount of data. Bin size of 0.01 was used for the construction of $1 \mathrm{D}$ histograms of $\log \left(\mathrm{G} / \mathrm{G}_{\mathrm{o}}\right)$ values from all conductance-distance curves without data selection. The bias voltage between the gold electrodes was set to $130 \mathrm{mV}$.

Electrochemical measurements. Cyclic voltammetry was used to investigate the self-assembled monolayers of the model 9,9'-spirobifluorene molecules on the gold bead electrodes in aqueous $\mathrm{NaOH}$ solutions (0.5 M). The self-assembly and the electrode preparation procedure are described in the Section 7 of the SI. Voltammetric experiments employed a true linear potential scan provided by the PGSTAT12 potentiostat (Metrohm, Switzerland). The electrode area was determined from the surface gold oxide reduction response in the aqueous sulfuric acid (0.1 M).

Computational Details. Density functional theory (DFT) and non-equilibrium Green's function formalism (NEGF) were used to obtain the transmission function $\mathrm{T}(E)$ and single molecule conductance values. ${ }^{29,30}$ All calculations of transmission function curves were carried out using the Amsterdam Density Functional (ADF) 
quantum chemistry package with PBEo hybrid exchange-correlation functional. $3^{1^{-}} 35$ A double- $\xi$ (DZ) basis set was used for the electrodes and a double- $\xi$ polarized (DZP) basis set was used for the molecule. Theoretical calculations in ADF were done with the incorporation of relativistic effects at the level of zeroorder regular approximation (ZORA) in a scalar relativistic form. ${ }^{36,37}$ Details concerning the model development and two computational methods used for the calculation of the transmission function $T(E)$ are specified in the Section 9 of the SI.

Theoretical conductance $\mathrm{G}$ was calculated using Landauer formula $\mathrm{G}=\mathrm{G}_{0} \times T\left(E_{F}\right)$ in the zero-bias approximation, where $\mathrm{G}_{0}$ is the conductance quantum and $T\left(E_{F}\right)$ the transmission function at the Fermi level $E_{\mathrm{F}}$ of the gold electrodes. 38,39 The Fermi level $E_{F}=-5.1 \pm 0.1 \mathrm{eV}$ against vacuum was taken from the experimentally obtained work function $\Phi$ for polycrystalline gold and within the experimental error matched that reported for the goldgold contacts. ${ }^{40,41}$

\section{RESULTS AND DISCUSSION}

Molecules $\mathbf{1}$ to 5 (see Chart 1) were synthesized for characterization of the charge transport pathways in the molecular wires containing a rigid 9,9'-spirobifluorene tripodal platform, capable of connecting to one of the electrodes by three thiol anchoring groups. Such platform possesses increased rigidity and stability compared to single anchors. It enables control over the spatial arrangement of the covalently attached arm with respect to the electrodes and decreases the number of relevant geometries in the single molecule junction for molecular electronics. In contrast to the platform structures reported so far, a superior electronic coupling of the rigid-rod subunit to the electrode is maintained due to the absence of $\mathrm{sp}^{3}$ carbon center in the conduction path. In particular, the covalent attachment of the arm in 7-position and the thiol anchor group in 2-position of the fluorene subunit guarantees a fully conjugated para-connection between the rigid rod and the gold substrate. ${ }^{26,27}$ Furthermore, the modular synthesis allows varying the functionalities embedded in the covalently attached arm. ${ }^{22,42}$

\section{Chart 1 Chemical Structure of Molecules 1 to 5}

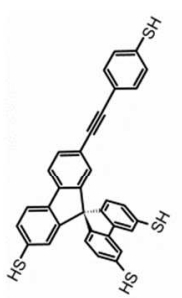

1

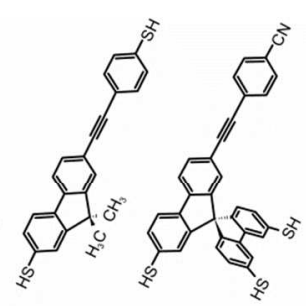

3

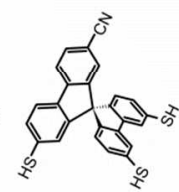

4

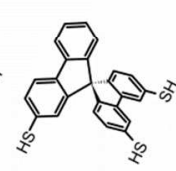

5
Molecules $\mathbf{1}$ and $\mathbf{3}$ contain 9,9'-spirobifluorene tripod with covalently attached phenylene ethynylene subunit representing the shortest oligophenylene ethynylene molecular wire. Molecule $\mathbf{1}$ is terminated with $\mathrm{SH}$ anchoring group and molecule $\mathbf{3}$ with $\mathrm{CN}$ anchor. Molecule $\mathbf{4}$ is a shorter derivative of $\mathbf{3}$ and consists of the 9,9'-spirobifluorene platform directly terminated by the nitrile group. Molecule 5 represents the reference system containing only the 9,9'-spirobifluorene tripod. Compound 2 has the same phenylene ethynylene subunit as $\mathbf{1}$, but instead of the rigid tripodal platform it contains the 9,9'-dimethylfluorene subunit, which preserves the conjugated backbone of molecule 1. Comparison of the conductance properties of molecules $\mathbf{1}$ and $\mathbf{2}$ aims at the experimental confirmation of the charge transport pathway along the phenylene ethynylene wire, whereas comparison of the single molecule conductance of molecules $\mathbf{1}$ and $\mathbf{3}$ aims at the evaluation of the role of the anchoring groups in tuning of the charge transport properties of the asymmetric molecules with the spirobifluorene platform.
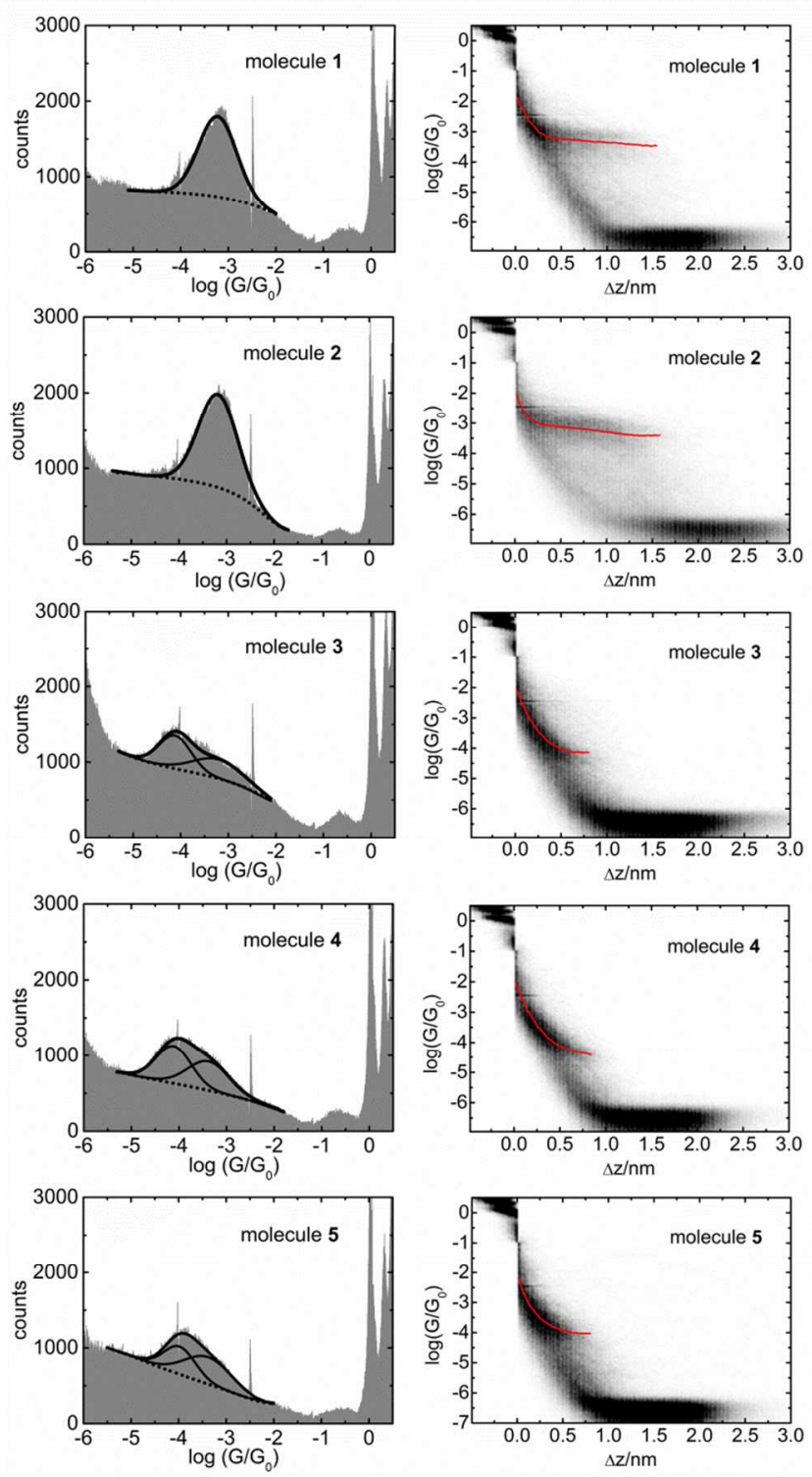

Figure 1 1D logarithmic conductance histograms (left panel) and 2D logarithmic conductance-distance histograms (right panel) of molecules 1 to 5 obtained by STMBJ technique at $25^{\circ} \mathrm{C}$ in mesitylene solvent containing $0.2 \mathrm{mM}$ of respective molecule. Probe retraction rate was $36 \mathrm{~nm} / \mathrm{s}$. 
Figure 1 shows the 1D logarithmic conductance histogram (left panel) and 2D logarithmic conductance-distance histogram (right panel) obtained by the STMBJ technique for molecules $\mathbf{1}$ to $\mathbf{5}$ in the mesitylene solvent at room temperature without any data selection. Corresponding 1D and 2D histograms constructed from the data obtained by the MCBJ technique are summarized in Section 6 of the SI. In all 1D histograms a peak at $\log \left(\mathrm{G} / \mathrm{G}_{\mathrm{O}}\right)=\mathrm{o}$ corresponds to the gold atomic contact formation, 43 whereas a small peak centered at $\log \left(\mathrm{G} / \mathrm{G}_{\mathrm{o}}\right)=-0.6$ can be assigned to the charge transport through the solvent molecule since it was not observed in STMBJ and MCBJ experiments performed in the air (Figure $\mathrm{S}_{5}$ in the SI). Both peaks were observed in the $1 \mathrm{D}$ conductance histogram of the mesitylene solvent in the absence of molecules $\mathbf{1}$ to $\mathbf{5}$ (Figure S6 in the SI). No other features were found in these conductance histograms serving as the evidence of a high level of cleanliness of the studied systems. Peaks observed at lower conductance values than $\log \left(\mathrm{G} / \mathrm{G}_{0}\right)=-0.6$ in Figure 1 were therefore unambiguously assigned to true molecular conductance features of the model molecules. Representative examples of the individual conductancedistance curves for molecules $\mathbf{1}$ to $\mathbf{4}$ are shown in Figure S7 of the SI.

2D logarithmic conductance-distance histograms in Figure 1 (right panel) can be viewed as an overlapping image of all experimentally obtained conductancedistance traces acquired during the elongation of MJs. Individual traces are horizontally aligned on a relative distance scale $\Delta \mathrm{z}$. The existence of the snapback region, in which the junction conductance drops steeply due to a sudden relaxation of gold atoms upon breaking of the last atomic contact, allows this kind of data representation to be constructed meaningfully. In this work, the value $\log \left(\mathrm{G} / \mathrm{G}_{\mathrm{O}}\right)=-\mathbf{1}$.0 was chosen to define the common point $\left[\log \left(\mathrm{G} / \mathrm{G}_{0}\right)=-1.0, \Delta \mathrm{z}=\mathrm{o} \mathrm{nm}\right]$ for all individual traces. Darker pixels indicate more frequently observed junction configurations. Regions with increased data density around $\log \left(\mathrm{G} / \mathrm{G}_{\mathrm{o}}\right)=\mathrm{o}$ and -0.6 represent charge transport through gold atomic contacts and through solvent molecule in the junction. Junctions containing investigated molecules give rise to plateaus at lower $\log \left(\mathrm{G} / \mathrm{G}_{\mathrm{o}}\right)$ values that correspond to peaks observed in 1D histograms. Upon breaking of the molecular junction, the conductance value drops down to the noise level, leading to increased data density below $\log \left(\mathrm{G} / \mathrm{G}_{0}\right)=-6$.

2D histograms reveal further details related to the $\mathrm{MJ}$ formation, evolution and breaking process. Red curves in Figure 1 represent the weighted average of the $\log \left(\mathrm{G} / \mathrm{G}_{0}\right)$ values obtained during the $\mathrm{MJ}$ elongation. Two different slopes are discernible in the molecular plateau region for all molecules studied, but they are different for molecules terminated by $\mathrm{SH}$ groups and $\mathrm{CN}$ groups. In the first case (molecules 1 and 2) a short initial segment (overlapping with the junction conductance measured in the absence of molecules) is followed by a long and less steep segment of decaying conductance. For CN terminated molecules ( $\mathbf{3}$ and $\mathbf{4}$ ) the first segment is significantly more pronounced followed by a rather short plateau of decaying conductance. Such a difference in the junction evolution for $\mathrm{SH}$ and $\mathrm{CN}$ terminated molecules has been observed for symmetric junctions possessing the same anchoring groups at both ends of the molecule. It was attributed to the lower binding energy of the $\mathrm{CN}-\mathrm{Au}$ bond as compared to the $\mathrm{S}-\mathrm{Au}$ bond. ${ }^{13}$ Since molecules 3 and 4 contain both $\mathrm{SH}$ and $\mathrm{CN}$ anchoring groups one can ask whether the molecular junction is formed by the attachment of thiolate terminated tripod and $\mathrm{CN}$ anchor. To answer this question molecule 5 that lacks the $\mathrm{CN}$ moiety was synthesized and its charge transport properties are also shown in Figure 1. It was found that $1 \mathrm{D}$ and $2 \mathrm{D}$ logarithmic conductance histograms are practically identical to those of molecules $\mathbf{3}$ and $\mathbf{4}$, i.e. the first segment is significantly more pronounced followed by a short plateau of decaying conductance. This result suggests that $\mathrm{CN}$ group does not play a role in the molecular junction evolution of molecules 3 to 4 .

Similar single molecule conductance results were obtained from MCBJ measurements (Figure S9 of the SI), which allow noise level suppression by one to two orders of magnitude compared to STMBJ. This technique enables studies of the later stages of the MJ evolution. Figure S9 shows additional maxima in the low conductance region for all studied molecules in $1 \mathrm{D}$ histograms, but no clear molecular plateaus could be resolved in the corresponding region of the $2 \mathrm{D}$ histograms. This indicates that no distinctly stable MJ configurations are connected with these low conductance states, which are most likely created by the pairs of molecules bridging the junction. The charge transport being secured by the intermolecular interactions between the phenylene rings of two molecules within the junction has been previously reported. ${ }^{15}$

Table 1 summarizes the single molecule conductance values (peak maxima and errors representing half of the FWHM values) in the high conductance region obtained by both STMBJ and MCBJ methods. Molecular conductance features in 1D histograms were fitted by one Gaussian for molecules $\mathbf{1}$ and $\mathbf{2}$ and by two Gaussians for molecules 3 and 5. The molecular conductance values obtained by both methods are in very good mutual agreement considering the differences in the experimental methodology. More importantly, the use of both methods ascertains the reliability of $\log \left(\mathrm{G} / \mathrm{G}_{0}\right)$ values reported in this paper. As the STMBJ approach (unlike MCBJ) offers a precise MJ length calibration, further discussion will be based on the STMBJ data.

Molecules $\mathbf{1}$ and $\mathbf{2}$ were designed to preserve the part of the molecule important for the charge transport along the molecular wire. Both molecules show the same single molecule conductance value $\log \left(\mathrm{G} / \mathrm{G}_{\mathrm{O}}\right)=-3.2 \pm 0.5$ indicating that the charge transport in molecule $\mathbf{1}$ favors the path along one fluorene unit of the spirobifluorene platform with covalently bound phenylene ethynylene molecular wire. The contribution of two thiolates connected to the main conductance path via the $\mathrm{sp}^{3}$ spiro carbon, i.e. placed on the second twisted fluorene unit of molecule 1, appears to be negligible even though the experimental evidence from the reductive desorption studies (Section 7 of the SI) indicates that the spirobi- 
Table 1. Theoretical and Experimental Parameters for Single Molecule Junctions and Selected MJ Configurations

\begin{tabular}{|c|c|c|c|c|c|c|}
\hline МJ & $\mathbf{L}_{M J} / \mathbf{n m}^{a}$ & $\mathrm{Zexp}_{\exp } / \mathbf{n m}^{b}$ & $\log \left(G / G_{0}\right)_{\mathrm{DFT}} c$ & $\log \left(G / G_{0}\right)_{\mathrm{DFT}} d$ & $\log \left(G / G_{0}\right)^{\text {STMBJ }}$ & $\log \left(G / G_{0}\right)^{M C B J}$ \\
\hline $\mathbf{1 a}$ & 1.4 & \multirow{4}{*}{$1.5 \pm 0.4$} & -3.0 & $-2.6 \pm 0.4$ & \multirow{4}{*}{$-3.2 \pm 0.5$} & \multirow{4}{*}{$-3.0 \pm 0.5$} \\
\hline $\mathbf{1 b}$ & 2.0 & & -3.7 & $-3.2 \pm 0.8$ & & \\
\hline 1c & 1.5 & & -5.4 & $-5.6 \pm 0.3$ & & \\
\hline 1d & 1.1 & & -4.2 & $-4.0 \pm 0.4$ & & \\
\hline $\mathbf{2 a}$ & 2.0 & $1.7 \pm 0.5$ & -3.2 & $-2.9 \pm 0.7$ & $-3.2 \pm 0.5$ & $-3.1 \pm 0.5$ \\
\hline $\mathbf{3 a}$ & 1.3 & \multirow{2}{*}{$1.3 \pm 0.3$} & -3.4 & $-3.4 \pm 0.1$ & \multirow{2}{*}{$-4.1 \pm 0.4$} & \multirow{2}{*}{$-3.9 \pm 0.5$} \\
\hline $\mathbf{3 b}$ & 1.1 & & $-4 \cdot 3$ & $-4.1 \pm 0.4$ & & \\
\hline $4 \mathbf{a}$ & 0.9 & \multirow{2}{*}{$1.3 \pm 0.2$} & -2.7 & $-2.7 \pm 0.1$ & \multirow{2}{*}{$-4.1 \pm 0.4$} & \multirow{2}{*}{$-4.1 \pm 0.8$} \\
\hline $4 b$ & 1.1 & & $-4 \cdot 3$ & $-4.1 \pm 0.4$ & & \\
\hline $5 \mathbf{a}$ & 1.1 & $1.3 \pm 0.3$ & -4.2 & $-4.0 \pm 0.4$ & $-4.0 \pm 0.4$ & - \\
\hline
\end{tabular}

a Theoretical MJ length LMJ = Ztheor $-0.25 \mathrm{~nm}$, where Ztheor is DFT calculated MJ length taken as a vertical distance between surface planes of two gold electrodes in the geometry optimized configurations shown in Chart 2, Chart 3 and in Figure S15 of SI.

${ }^{b}$ Experimental MJ length zexp is the sum of the characteristic length (relative displacement) $\Delta \mathrm{z}$ (Figure 2) and the snap-back distance $\mathrm{z}_{\text {corr }}=0.4 \mathrm{~nm}$, i.e. $\mathrm{z}_{\exp }=\Delta \mathrm{z}+\mathrm{z}_{\text {corr. }}$. Characteristic length calculations were done at $\log \left(\mathrm{G}^{\#} / \mathrm{G}_{0}\right)=-5 \cdot 5$.

$c$ DFT calculated $\log \left(\mathrm{G} / \mathrm{G}_{0}\right)$ obtained from transmission functions shown in Figure $\mathrm{S} 17$ of SI at E-EF $=0 \mathrm{eV}$

${ }^{d}$ DFT calculated $\log \left(\mathrm{G} / \mathrm{G}_{\mathrm{O}}\right)$ obtained from transmission functions in the interval $\mathrm{E}-\mathrm{E}_{\mathrm{F}}= \pm 0.1 \mathrm{eV}$.

fluorene tripod is attached to the gold substrate by all three thiol groups.

Let us compare now the single molecule conductance of molecules $\mathbf{1}$ and $\mathbf{3}$. They both contain the 9,9'spirobifluorene tripod but they differ in the type of the anchoring group located on the opposite side of the molecule. Such a small structural difference has an important impact on their conductance properties. Thiol-terminated molecule $\mathbf{1}$ shows a clear narrow molecular conductance peak at $\log \left(\mathrm{G} / \mathrm{G}_{0}\right)=-3.2 \pm 0.5$, whereas nitrile-terminated molecule $\mathbf{3}$ exhibits a relatively broad conductance feature that was fitted by two Gaussians centered at $\log \left(\mathrm{G} / \mathrm{G}_{0}\right)=-3.2 \pm 0.6$ and $\log \left(\mathrm{G} / \mathrm{G}_{0}\right)=$ $-4.1 \pm 0.4$ (see Figure 1). Identical $\log \left(\mathrm{G} / \mathrm{G}_{0}\right)$ characteristics were observed for SAMs of molecule $\mathbf{3}$ (see Figure S11 of the SI). The former maximum is associated with the inclined segment of the molecular plateau pertaining to the early stages of the MJ evolution and represents the contribution from the through solvent tunneling. The maximum at $\log \left(\mathrm{G} / \mathrm{G}_{0}\right)=-4.1 \pm 0.4$ is related to the short plateau observed at the later stage of the MJ evolution and represents true single molecule conductance of molecule $\mathbf{3}$ (see Table 1 ). This value is almost one order of magnitude lower than the conductance of molecule $\mathbf{1}$. Even though the molecules $\mathbf{4}$ and $\mathbf{5}$ are much shorter than molecule $\mathbf{3}$, they show the same conductance distribution profiles. The true molecular conductance value gave maximum at $\log \left(\mathrm{G} / \mathrm{G}_{0}\right)=-4.1 \pm 0.4$ for 4 and $\log \left(\mathrm{G} / \mathrm{G}_{0}\right)=-4.0 \pm 0.4$ for 5 . This indicates that the charge transport is length independent for molecules $\mathbf{3}$ to 5 and does not involve the $\mathrm{CN}$ moiety.
2D histograms from the STMBJ measurements were further subjected to the characteristic length analysis aimed at determining the average distance $\Delta \mathrm{z}$, to which the MJ can be elongated before the breaking event. Figure 2 shows histograms of the most probable $\Delta \mathrm{z}$ values representing the $\mathrm{MJ}$ characteristic length for molecules $\mathbf{1}$ to 5. It was constructed from $2 \mathrm{D}$ logarithmic conductance-distance histograms in Figure 1. At first a certain $\log \left(\mathrm{G}^{\#} / \mathrm{G}_{0}\right)$ value below the molecular conductance feature was selected and the horizontal cross-section of the $2 \mathrm{D}$ histogram at this value was plotted in the form of the number of counts as a function of the distance $\Delta \mathrm{z}$. By this procedure the histograms in Figure 2 were constructed at $\log \left(\mathrm{G}^{\#} / \mathrm{G}_{0}\right)=-5 \cdot 5$. All five distributions were fitted by a pair of Gaussian peaks, reflecting the existence of true molecular junctions $\Delta \mathrm{z}$ (higher values) and junctions in which no molecules were trapped $\Delta \mathrm{z}_{\mathrm{o}}$ (lower values). No significant variation of the values for $\Delta z_{0}$ was observed (see also Table S1, SI), whereas the values of $\Delta \mathrm{z}$ were found to depend on the chemical structure of the molecule. The aim of this analysis is to determine the experimental molecular junction length $\mathrm{Z}_{\mathrm{exp}}$, which could be directly compared with theoretical predictions.

The experimental MJ length is given by $\mathrm{Z}_{\exp }=\Delta \mathrm{z}+\mathrm{Z}_{\mathrm{corr}}$, where $\mathrm{Z}_{\text {corr }}$ is the snapback distance, which was determined to be $0.4 \mathrm{~nm}$ in our experiments and is in excellent agreement with $\mathrm{z}_{\text {corr }}$ values obtained previously. ${ }^{10,13,44}$ Details on the experimental determination of $\mathrm{Z}_{\text {corr }}$ are given in Figure S8 of the SI. Experimental MJ length $Z_{\exp }$ values are given in Table 1. More detailed analysis of the molecular junction formation, evolution and breaking requires comparison of the experimental 
Zexp values with the calculated molecular junction length Ztheor obtained by the quantum chemical modeling. Direct comparison between experiment and theory requires further correction of $Z_{\text {theor }}$ for the minimum electrode separation distance $\mathrm{d}_{\mathrm{Au}-\mathrm{Au}}=0.25 \mathrm{~nm}$, defined as a distance between the centers of two gold atoms forming apexes of two electrodes in the absence of molecules. 45 This value is subtracted from $\mathrm{Z}_{\text {theor }}$ to obtain the theoretical molecular junction length $\mathrm{L}_{\mathrm{MJ}}=\mathrm{Z}_{\mathrm{theor}}-\mathrm{d}_{\mathrm{Au}-\mathrm{Au}}$ directly comparable with the experimental $z_{\exp }$ values. Due to the existence of three thiol moieties at one side of the molecules 1, 3, 4 and 5, the theoretical calculations carried out in this work consider electrodes with atomically flat gold surfaces instead of single apex atoms in order to render the electrodes capable of binding multiple $\mathrm{SH}$ groups. Therefore, the Ztheor values were determined in various junction configurations as a perpendicular distance between the surface atomic layers of the two electrodes. Above-mentioned analysis does not include the situation when a gold atom is abstracted from the gold surface together with the molecule during the MJ breaking process as has been postulated recently by Tao et al.46,47 based on their combined single molecule conductance and MJ breaking force measurements of thiolterminated molecules. Authors admitted that their suggestion is based on the experimentally observed breaking force value identical to the $\mathrm{Au}-\mathrm{Au}$ bond breaking force for the gold-gold junctions without molecules, but they did not exclude the possibility that the same force may reflect the S-Au bond breaking. Therefore, we did not use this further correction. Theoretical MJ length values $\mathrm{L}_{\mathrm{MJ}}$ are summarized in Table 1 for selected MJ configurations of molecules $\mathbf{1}$ to $\mathbf{5}$.
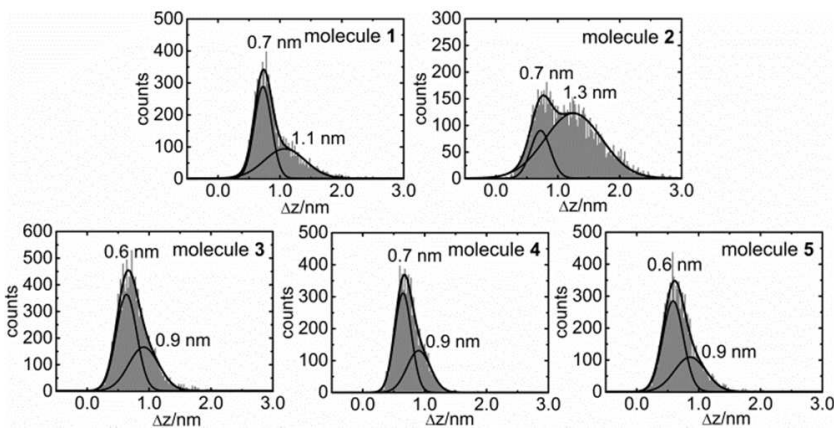

Figure 2. Characteristic length analysis of the STMBJ conductance-distance curves without data selection for molecules 1 to 5. Junctions were formed at $25^{\circ} \mathrm{C}$ in mesitylene solvent. Analysis was performed at $\log \left(G^{\#} / G_{0}\right)=-5.5$.

Quantum chemical calculations implemented different computational models depending on the type of the anchoring groups involved in the MJ formation. First model was used for MJs that were formed by SH anchoring groups only and was used for conductance value calculations for molecules $\mathbf{1}$ to 5, whereas two additional models were used for MJs containing both $\mathrm{SH}$ and $\mathrm{CN}$ anchors and provided theoretical single molecule conductance values for molecules $\mathbf{3}$ and $\mathbf{4}$. Model development details and description of the quantum chemical methods are given in the Experimental part and Section 9 of the SI. The resulting optimized junction geometries for computational models and methods are summarized through Section 9 to 13 of the SI together with the calculated transmission functions $T(E)$, single molecule junction conductance values represented as $\log \left(\mathrm{G} / \mathrm{G}_{0}\right)$, HOMO and LUMO energies of the extended molecule system and the molecule-localized molecular orbitals that represent the most probable transport channel including the tables of the corresponding molecular orbital energies. The $\mathrm{L}_{\mathrm{MJ}}$ and theoretical $\log \left(\mathrm{G} / \mathrm{G}_{0}\right)^{\mathrm{DFT}}$ values in Table 1 refer to model one in the case of MJ configurations $1 \mathrm{a}-1 \mathrm{~d}, 2 \mathrm{a}, 3 \mathrm{~b}, 4 \mathrm{~b}$ and $5 \mathrm{a}$ and to model two in the case of MJ configurations $3 \mathrm{a}$ and $4 \mathrm{a}$.

\section{Chart 2 Geometry optimized MJ configurations of tripodal molecule 1 assuming different charge transport pathways.}

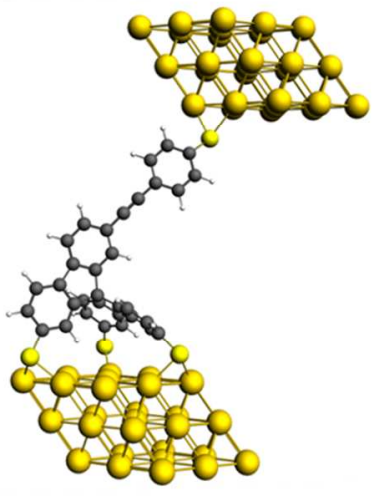

1a

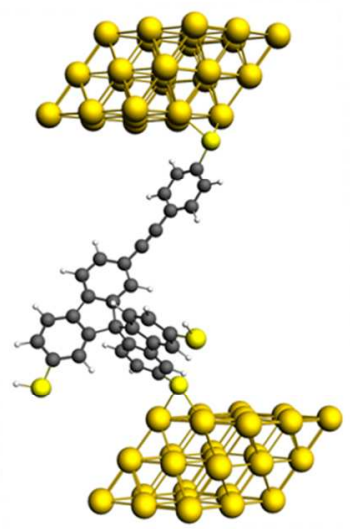

1c

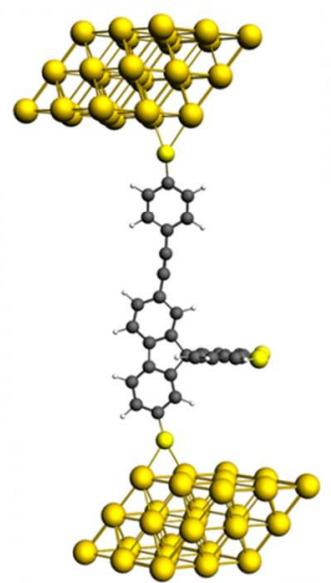

1b

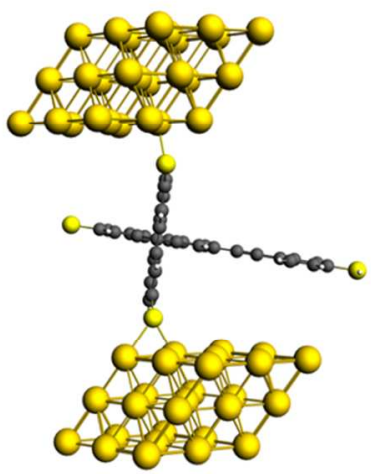

1d
Chart 2 shows four geometry optimized MJ configurations for molecule 1, whereas MJ configurations for molecule 2 are given in Figure S15 of the SI and for molecules 3 to 5 in the Chart 3. Configurations 1a to $1 \mathrm{~d}$ represent four possible cases where the charge transport pathways are dictated by different modes of the molecular attachment to gold leads. 
Four geometry optimized MJ configurations for molecule $\mathbf{1}$ in Chart 2 represent distinctly different charge transport pathways. Configurations $1 \mathrm{a}$ and $1 \mathrm{~b}$ favor transport through the fluorene unit and phenylene ethynylene molecular wire. Their $\mathrm{L}_{\mathrm{MJ}}$ values differ significantly due to the different number of contact points via the thiolate-gold bonds. Configuration 1c represents possible charge transport path through the $\mathrm{sp}^{3}$ carbon of the 9,9'-spirobifluorene tripod and molecular wire, whereas configuration $1 \mathrm{~d}$ favors charge transport through the terminal thiolate groups of the 9,9spirobifluorene tripod itself.

\section{Chart 3 Geometry optimized MJ configurations of tripodal molecules 3 to 5 assuming different charge transport pathways.}

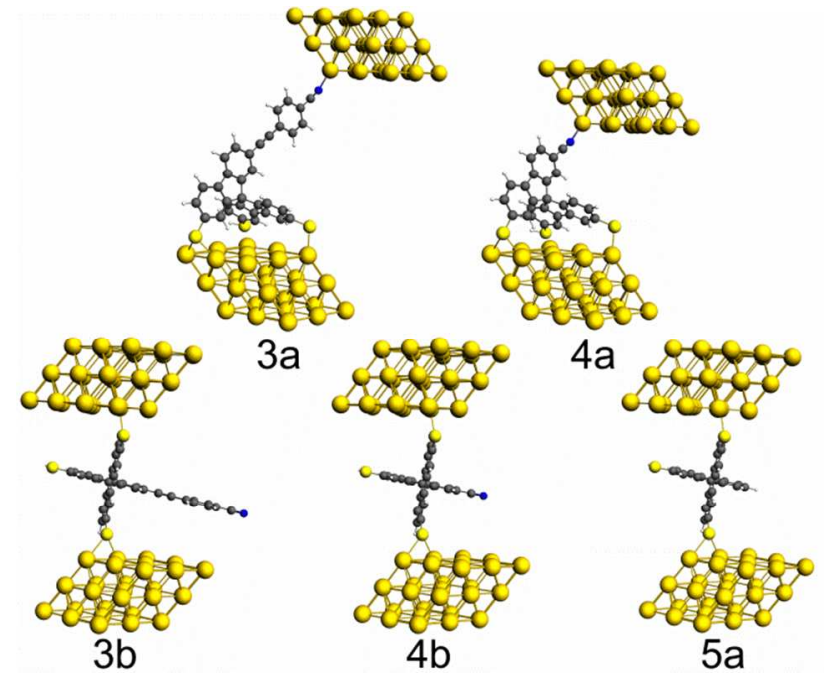

Comparison of the theoretically obtained molecular conductance and LMJ values of these four configurations with experimental data in Table 1 aims at the elucidation of the most probable charge transport pathway in the asymmetric molecules with the spirobifluorene platform. The experimental MJ length value of molecule $\mathbf{1}$ $\left(\mathrm{Z}_{\exp }=1.5 \pm 0.4 \mathrm{~nm}\right)$ is in perfect agreement with the theoretically predicted $\mathrm{MJ}$ length value obtained for configurations $1 \mathrm{a}\left(\mathrm{L}_{\mathrm{MJ}}=1.4 \mathrm{~nm}\right)$ and $1 \mathrm{c}\left(\mathrm{L}_{M J}=1.5 \mathrm{~nm}\right)$. On the other hand, the LMJ values obtained for configurations $1 \mathrm{~b}(2.0 \mathrm{~nm})$ and $1 \mathrm{~d}(1.1 \mathrm{~nm})$ do not fit well to experimental data. Therefore, these two configurations are not likely to exist in MJ experiments. Though the theoretical and experimental MJ length is identical for the configuration $1 \mathrm{c}$, its theoretical conductance value is more than two orders of magnitude lower than the experimentally obtained conductance value for $\mathbf{1}$, excluding thus the existence of this configuration in MJs as well. Theoretically predicted conductance for configuration 1a $\log \left(\mathrm{G} / \mathrm{G}_{\mathrm{o}}\right)_{\mathrm{DFT}}=-3.0$ compares very well with the experimentally obtained conductance values for molecule $\mathbf{1}$ (see Table 1). Our combined experimental and theoretical approach confirms that the configuration 1a represents the most probable MJ configuration in the course of the junction formation and evolution. Junctions containing molecules $\mathbf{1}$ and $\mathbf{2}$ have identical conductance values, but MJs of molecule 2 give larger experimental length $\mathrm{Z}_{\exp }=1.7 \pm 0.5 \mathrm{~nm}$, which is closer to predicted $\mathrm{L}_{\mathrm{MJ}}$ value of $2.0 \mathrm{~nm}$ (Table 1 and Figure S15 of the SI). Identical conductance values of $\mathbf{1}$ and $\mathbf{2}$ provide additional experimental verification of the charge transport path in molecule 1. Junctions containing molecule $\mathbf{3}$ show lower $Z_{\exp }$ value $(1.3 \pm 0.3 \mathrm{~nm})$ than junctions containing molecule $\mathbf{1}(1.5 \pm 0.4 \mathrm{~nm})$. The $Z_{\exp }$ value for 3 is identical to that observed for molecules 4 and 5 . This result provided further experimental confirmation that all three molecules $\mathbf{3}$ to $\mathbf{5}$ have the same charge transport pathway independent of the length of the molecule. Chart 3 summarizes considered MJ configurations for molecules 3 to 5. Configurations $3 \mathrm{a}$ and $4 \mathrm{a}$ represent $\mathrm{MJ}$ consisting of a 9,9'-spirobifluorene tripod attached to one of the electrodes and $\mathrm{CN}$ terminus attached to the second one. Configurations $3 \mathrm{~b}, 4 \mathrm{~b}$ and $5 \mathrm{a}$ represent the $\mathrm{MJ}$ formed by two thiolate groups of the tripod. Theoretically-obtained molecular conductance and LMJ values of these five configurations for molecules $\mathbf{3}$ to $\mathbf{5}$ are given in Table 1. Comparison of theoretical and experimental molecular conductance and LMJ values confirms that the most probable charge transport pathway for molecules $\mathbf{3}$ to 5 is through two thiolate anchors of the spirobifluorene units (configurations $3 \mathrm{~b}, 4 \mathrm{~b}$ and $5 \mathrm{a}$ ).

Our results confirmed that spirobifluorene tripod can be used as a modular platform in molecular electronics. As showed by electrochemical reductive desorption measurements the tripod is covalently attached to the gold support by all three thiolate groups and forms selfassembled monolayers on the electrode surface. Break junction measurement strives for addressing only one molecule out of this ensemble. We have shown that in the case of SH-terminated molecule $\mathbf{1}$ (using molecule $\mathbf{2}$ as a reference) the charge is transported through the fluorene unit of the spirobifluorene tripod and phenylene ethynylene molecular wire. On the other hand, in the CN-terminated molecules $\mathbf{3}$ and $\mathbf{4}$ (using molecule 5 as a reference) the main charge transport path is through the thiolate bonded anchors of the 9,9'-spirobifluorene tripod. This difference in the conductance pathway is reflected in an order of magnitude different single molecule conductance values between molecule $\mathbf{1}$ and $\mathbf{3}$. This result is a direct consequence of the differences between the binding energies of the $\mathrm{S}-\mathrm{Au}$ and $\mathrm{CN}-\mathrm{Au}$ bonds reported in the literature. 45

\section{CONCLUSION}

Charge transport pathways in single molecule junctions of molecules containing spirobifluorene subunits were investigated by the STMBJ and MCBJ techniques and the obtained results were compared with quantum chemical calculations. Combined electrochemical, break junction and quantum chemical approach confirmed that the most probable MJ configuration for molecule $\mathbf{1}$ is that involving all three thiolate groups of the 9,9'spirobifluorene platform. Furthermore, quantum chemical calculations confirmed that the conjugated backbone represents the dominant transport channel in molecules 
$\mathbf{1}$ and 2. Variation of the terminal anchor group in molecules $\mathbf{1}$ and $\mathbf{3}$ enables tuning of the charge transport path due to changes of the preferred binding geometries of the tripodal 9,9'-spirobifluorene platform to the gold leads. Contrary to molecule 1 molecules $\mathbf{3}$ and $\mathbf{4}$ do not contact the electrode by their $\mathrm{CN}$ termini and it was shown that the charge transport path includes two thiolate anchors of the 9,9'-spirobifluorene platform. This is a direct consequence of the different binding energies of the $\mathrm{S}-\mathrm{Au}$ and $\mathrm{CN}-\mathrm{Au}$ bonds. This conclusion was further supported by the inspection of the charge transport characteristics of the reference molecule 5 possessing no $\mathrm{CN}$ terminus, which showed features identical to those of molecules 3 and $\mathbf{4}$. We are currently exploring the potential of this new modular 9,9'-spirobifluorene platform for improved spatial control over the molecular architecture and for enabling different functionalities (switching, diode-like behavior) of thus created asymmetric junctions.

\section{ASSOCIATED CONTENT}

Supporting Information. STMBJ and MCBJ setup details; STMBJ measurements for mesitylene; STMBJ conductance curves for molecules; characteristic length analysis; MCBJ results; reductive desorption studies; STMBJ measurement of self-assembled monolayer of molecule $\mathbf{3}$; computational details and model development; optimized molecular junction geometries; molecular orbitals and energies; transmission functions; theoretical conductance values. This material is available free of charge via the Internet at http://pubs.acs.org.

\section{AUTHOR INFORMATION}

\section{Corresponding Authors}

For transport studies: *hromadom@jh-inst.cas.cz; for molecular design and syntheses:_*marcel.mayor@unibas.ch

\section{Author Contributions}

The manuscript was written through contributions of all authors. ${ }^{\Delta}$ These authors contributed equally.

\section{ACKNOWLEDGMENT}

G.M. acknowledges the support from Hungarian funding agency OTKA (K112034 and K105735). M.H. and V.K. acknowledge the support from the Czech Science Foundation (14-05180S, 16-0746oY). M.H. and G.M. the joint project support between Hungarian and Czech Academy of Sciences (HU/2013/O5 and MTA-16-02). M.V. and M.M. acknowledge financial support by the research network »Functional Nanostructures « of the Baden-Württemberg Stiftung and by the Helmholtz Research Program STN (Science and Technology of Nanosystems). M.V. and M.M. also thank the Institute of Nanotechnology (INT), Karlsruhe Institute of Technology (KIT) for ongoing support. W.H. and M.M. thank the European FP7-ITN network MOLESCO.

\section{REFERENCES}

(1) Wang, C. S.; Batsanov, A. S.; Bryce, M. R.; Martín, S.; Nichols, R. J.; Higgins, S. J.; García-Suárez, V. M.; Lambert, C. J. Oligoyne Single Molecule Wires. J. Am. Chem. Soc. 2oo9, 131, 15647-15654.
(2) Zhao, X.; Huang, C.; Gulcur, M.; Batsanov, A. S.; Baghernejad, M.; Hong, W.; Bryce, M. R.; Wandlowski, T. Oligo(aryleneethynylene)s with Terminal Pyridyl Groups: Synthesis and Length Dependence of the Tunneling-to-Hopping Transition of Single-Molecule Conductances. Chem. Mater. 2013, 25, 4340-4347.

(3) Hines, T.; Diez-Perez, I.; Hihath, J.; Liu, H.; Wang, Z.; Zhao, J.; Zhou, G.; Müllen, K.; Tao, N. Transition from Tunneling to Hopping in Single Molecular Junctions by Measuring Length and Temperature Dependence. J. Am. Chem. Soc. 2010, 132, 11658-11664.

(4) Capozzi, B.; Dell, E. J.; Berkelbach, T. C.; Reichman, D. R.; Venkataraman, L.; Campos, L. M. Length-Dependent Conductance of Oligothiophenes. J. Am. Chem. Soc. 2014, 136, 10486-10492.

(5) Venkataraman, L.; Klare, J. E.; Nuckolls, C.; Hybertsen, M. S.; Steigerwald, M. L. Dependence of Single-Molecule Junction Conductance on Molecular Conformation. Nature 2oo6, 442, 904-907.

(6) Li, Z.; Pobelov, I.; Wandlowski, T.; Bagrets, A.; Arnold, A.; Evers, F. Charge Transport in Single Au | Alkanedithiol | Au Junctions: Coordination Geometries and Conformational Degrees of Freedom. J. Am. Chem. Soc. 2008, 13O, 318-326.

(7) Mishchenko, A.; Zotti, L. A.; Vonlanthen, D.; Bürkle, M.; Pauly, F.; Cuevas, J. C.; Mayor, M.; Wandlowski, T. SingleMolecule Junctions Based on Nitrile-Terminated Biphenyls: A Promising New Anchoring Group. J. Am. Chem. Soc. 2011, 133, 184-187.

(8) Mishchenko, A.; Vonlanthen, D.; Meded, V.; Bürkle, M.; Li, Ch.; Pobelov, I. V.; Bagrets, A.; Viljas, J. K.; Pauly, F.; Evers, $\mathrm{F}$. et al. Influence of Conformation on Conductance of Biphenyl-Dithiol Single-Molecule Contacts. Nano Lett. 2010, 10 , $156-163$.

(9) Cui, L.; Liu, B.; Vonlanthen, D.; Mayor, M.; Fu, Y.; Li, J. F.; Wandlowski, T. In Situ Gap-Mode Raman Spectroscopy on Single-Crystal $\mathrm{Au}(100)$ Electrodes: Tuning the Torsion Angle of 4,4'-Biphenyldithiols by an Electrochemical Gate Field. J. Am. Chem. Soc. 2011, 133, 7332-7335.

(10) Kaliginedi, V.; Moreno-García, P.; Valkenier, H.; Hong, W.; García-Suárez, V. M.; Buiter, P.; Otten, J. L. H.; Hummelen, J. C.; Lambert, C. J.; Wandlowski, T. Correlations between Molecular Structure and Single-Junction Conductance: A Case Study with Oligo(phenylene-ethynylene)-Type Wires. $J$. Am. Chem. Soc. 2012, 134, 5262-5275.

(11) Kolivoška, V.; Valášek, M.; Gál, M.; Sokolová, R.; Bulíčková, J.; Pospíšil, L.; Mészáros, G.; Hromadová, M. SingleMolecule Conductance in a Series of Extended Viologen Molecules. J. Phys. Chem. Lett. 2013, 4, 589-595.

(12) Dell, E. J.; Capozzi, B.; Xia, J.; Venkataraman, L.; Campos, L. M. Molecular Length Dictates the Nature of Charge Carriers in Single-Molecule Junctions of Oxidized Oligothiophenes. Nature Chem. 2015, 7, 209-214.

(13) Hong, W.; Manrique, D. Z.; Moreno-García, P.; Gulcur, M.; Mishchenko, A.; Lambert, C. J.; Bryce, M. R.; Wandlowski, T. Single Molecular Conductance of Tolanes: Experimental and Theoretical Study on the Junction Evolution Dependent on the Anchoring Group. J. Am. Chem. Soc. 2012, 134, 2292-2304.

(14) Balachandran, J.; Reddy, P.; Dunietz, B. D. ; Gavini, V. End-Group-Induced Charge Transfer in Molecular Junctions: Effect on Electronic-Structure and Thermopower. J. Phys. Chem. Lett. 2012, 3, 1962-1967.

(15) Wu, S.; González, M. T.; Huber, R.; Grunder, S.; Mayor, M.; Schönenberger, Ch.; Calame, M. Molecular Junctions Based on Aromatic Coupling. Nat. Nanotech. 2oo8, 3, 569-574.

(16) Yoshida, K.; Pobelov, I.; Manrique, D. Z.; Pope, T.; Mészáros, G.; Gulcur, M.; Bryce, M. R.; Lambert, C. J.; Wandlowski, T. Correlation of Breaking Forces, Conductances and Geometries of Molecular Junctions. Sci. Rep. 2015, 5, 9002. 
(17) Kolivoška, V.; Mohos, M.; Pobelov, I. V.; Rohrbach, S.; Yoshida, K.; Hong, W. J.; Fu, Y. C.; Moreno-García, P.; Mészáros, G.; Broekmann, P. et al. Electrochemical Control of a Non-covalent Binding Between Ferrocene and Betacyclodextrin. Chem. Commun. 2014, 50, 11757-11759.

(18) Ponce, I.; Aragonès, A. C.; Darwish, N.; Pla-Vilanova, P.; Oñate, R.; Caroli Rezende, M.; Zagal, J. H.; Sanz, F.; Pavez, J.; Díez-Pérez, I. Building Nanoscale Molecular Wires Exploiting Electrocatalytic Interactions. Electrochim. Acta 2015, 179, 611-617.

(19) Wei, Z.; Wang, X.; Borges, A.; Santella, M.; Li, T.; Sørensen, J. K.; Vanin, M.; Hu, W.; Liu, Y.; Ulstrup, J. et al. Triazatriangulene as Binding Group for Molecular Electronics. Langmuir 2014, 3O, 14868-14876.

(20) Hammerich, M.; Rusch, T.; Krekiehn, N. R.; Bloedorn, A.; Magnussen, O. M.; Herges R. Imine-Functionalized Triazatriangulenium Platforms: Towards an Artificial Ciliated Epithelium. Chem. Phys. Chem. 2016, 17, 1870-1874.

(21) Ie, Y.; Hirose, T.; Yao, A.; Yamada, T.; Takagi, N.; Kawai, M.; Aso, Y. Synthesis of Tripodal Anchor Units Bearing Selenium Functional Groups and Their Adsorption Behaviour on Gold. Phys. Chem. Chem. Phys. 2009, 11, 4949-4951.

(22) Ie, Y.; Tanaka, K.; Tashiro, A.; Lee, S. K.; Testai, H. R.; Yamada, R.; Tada, H.; Aso, Y. Thiophene-based Tripodal Anchor Units for Hole Transport in Single-Molecule Junctions with Gold Electrodes. J. Phys. Chem. Lett. 2o15, 6, 3754-3759.

(23) Ie, Y.; Hirose, T.; Nakamura, H.; Kiguchi, M.; Takagi, N.; Kawai, M.; Aso, Y. Nature of Electron Transport by Pyridine-Based Tripodal Anchors: Potential for Robust and Conductive Single-Molecule Junctions with Gold Electrodes. J. Am. Chem. Soc. 2011, 133, 3014-3022.

(24) Valášek, M.; Lindner, M.; Mayor, M. Rigid Multipodal Platforms for Metal Surfaces. Beilstein J. Nanotechnol. 2016, 7, 374-405.

(25) Lindner, M.; Valášek, M.; Homberg, J.; Edelmann, K.; Gerhard, L.; Wulfhekel, W.; Fuhr, O.; Wächter, T.; Zharnikov, M.; Kolivoška, V. et al. Importance of the Anchor Group Position (Para versus Meta) in Tetraphenylmethane Tripods: Synthesis and Self-Assembly Features. Chem. Eur. J. 2016, 22, 13218-13235.

(26) Valášek, M.; Edelmann, K.; Gerhard, L.; Fuhr, O.; Lukas, M.; Mayor, M. Synthesis of Molecular Tripods Based on a Rigid 9,9'-Spirobifluorene Scaffold. J. Org. Chem. 2014, 79, 7342-7357.

(27) Karimi, M. A.; Bahoosh, S. G.; Valášek, M.; Bürkle, M.; Mayor, M.; Pauly, F.; Scheer, E. Identification of the Current Path for a Conductive Molecular Wire on a Tripodal Platform. Nanoscale 2016, 8, 10582-10590.

(28) Pobelov, I. V. Electron Transport Studies - An Electrochemical Scanning Tunneling Microscopy Approach. Ph.D. Dissertation, RWTH Aachen University, Germany, 2008.

(29) Verzijl, C. J. O.; Seldenthuis, J. S.; Thijssen, J. M. Applicability of the Wide-Band Limit in DFT-based Molecular Transport Calculations. J. Chem. Phys. 2013, 138, 094102.

(30) Verzijl, C. J. O.; Thijssen, J. M. DFT-Based Molecular Transport Implementation in ADF/BAND. J. Phys. Chem. C 2012, 116, 24393-24412.

(31) Fonseca Guerra, C.; Snijders, J. G.; te Velde, G.; Baerends, E. J. Towards an Order-N DFT Method. Theor. Chem. Acc. 1998, 99, 391-403.
(32) te Velde, G.; Bickelhaupt, F. M.; van Gisbergen, S. J. A.; Fonseca Guerra, C.; Baerends, E. J.; Snijders, J. G.; Ziegler, T. Chemistry with ADF. J. Comput. Chem. 2oo1, 22, 931-967.

(33) te Velde, G.; Baerends, E. J. Precise Density-Functional Method for Periodic Structures. Phys. Rev. B 1991, 44, 78887903.

(34) Wiesenekker, G.; Baerends, E. J. Quadratic Integration over the Three-Dimensional Brillouin Zone. J. Phys. Condens. Matter 1991, 3, 6721-6742.

(35) Adamo, C.; Barone, V. Toward Reliable Density Functional Methods Without Adjustable Parameters: The PBEo Model. J. Chem. Phys. 1999, 110, 6158-6169.

(36) van Lenthe, E.; Baerends, E. J.; Snijders, J. G. Relativistic Total Energy Using Regular Approximations. J. Chem. Phys. 1994, 101, 9783-9792.

(37) van Lenthe, E.; Ehlers, A.; Baerends, E. J. Geometry Optimizations in the Zero Order Regular Approximation for Relativistic Effects. J. Chem. Phys. 1999, 110, 8943-8953.

(38) Landauer, R. Conductance Determined by Transmission: Probes and Quantised Constriction Resistance. J. Phys. Condens. Matter 1989, 1, 8099-8110.

(39) S. Datta, Electronic Transport in Mesoscopic Systems, Cambridge University Press, Cambridge, 1995.

(40) Veenstra, S. C.; Stalmach, U.; Krasnikov, V. V.; Hadziioannoua, G.; Jonkman, H. T.; Heeres, A.; Sawatzky, G. A. Energy Level Alignment at the Conjugated Phenylene-Vinylene Oligomer/Metal Interface. Appl. Phys. Lett. 2000, 76, 2253-2255.

(41) Trouwborst, M. L.; Huisman, E. H.; Bakker, F. L.; van der Molen, S. J. van Wees, B. J. Single Atom Adhesion in Optimized Gold Nanojunctions. Phys. Rev. Lett. 2008, 10o, 175502.

(42) Chinwangso, P.; Jamison, A. C.; Lee, T. R. Multidentate Adsorbates for Self-Assembled Monolayer Films. Acc. Chem. Res. 2011, 44, 511-519.

(43) Agraï, N.; Yeyati, A. L.; van Ruitenbeek, J. M. Quantum Properties of Atomic-Sized Conductors. Phys. Rep. 2oo3, 377, 81-279.

(44) Zhao, J.; Murakoshi, K.; Yin, X.; Kiguchi, M.; Guo, Y.; Wang, N.; Liang, S.; Liu, H. Dynamic Characterization of the Postbreaking Behavior of a Nanowire. J. Phys. Chem. C 2oo8, 112, 20088-20094.

(45) Moreno-Garcia, P.; Gulcur, M.; Manrique, D. Z.; Pope, T.; Hong, W.; Kaliginedi, V.; Huang, C.; Batsanov, A. S.; Bryce, M. R.; Lambert, C. et al. Single-Molecule Conductance of Functionalized Oligoynes: Length Dependence and Junction Evolution. J. Am. Chem. Soc. 2013, 135, 12228-12240.

(46) Xu, B.; Xiao, X.; Tao, N. J. Measurements of SingleMolecule Electromechanical Properties. J. Am. Chem. Soc. 2003, 125, 16164-16165.

(47) Li, X.; He, J.; Hihath, J.; Xu, B.; Lindsay, S. M.; Tao, N. Conductance of Single Alkanedithiols: Conduction Mechanism and Effect of Molecule-Electrode Contacts. J. Am. Chem. Soc. 2006, 128, 2135-2141. 
TOC graphics:

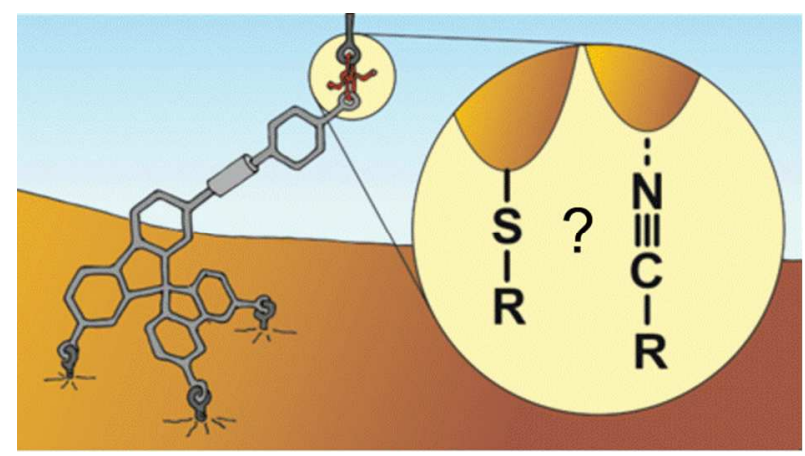




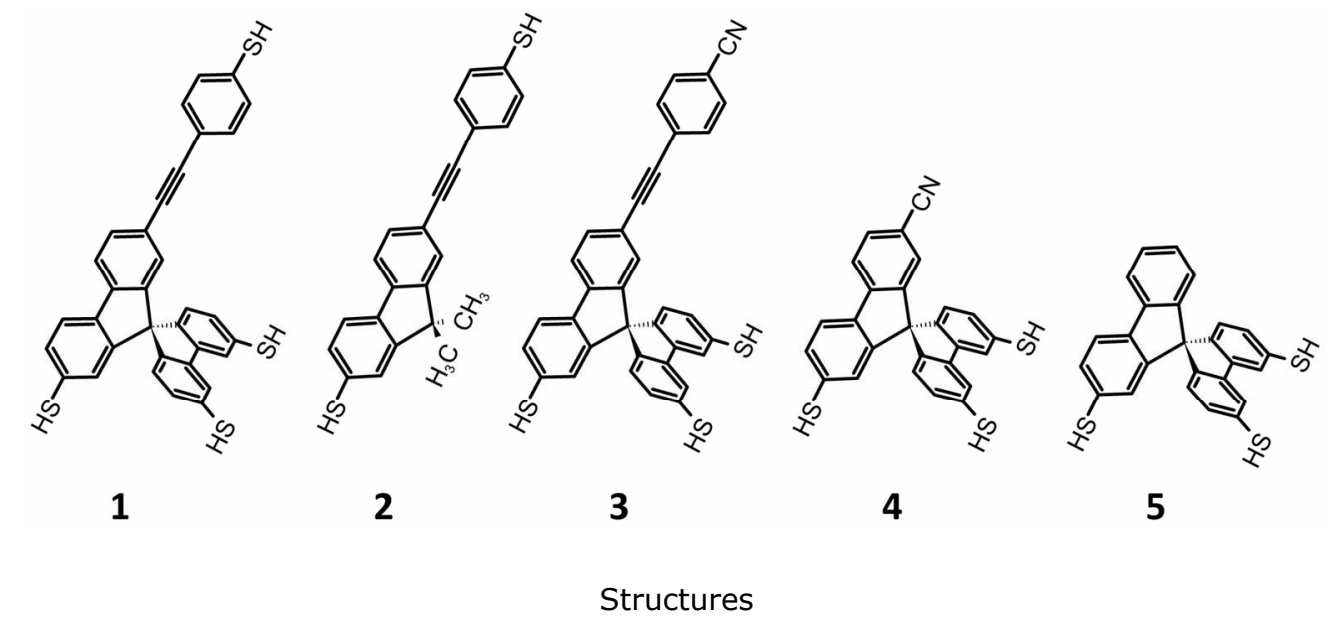

$74 \times 29 \mathrm{~mm}(600 \times 600$ DPI $)$ 

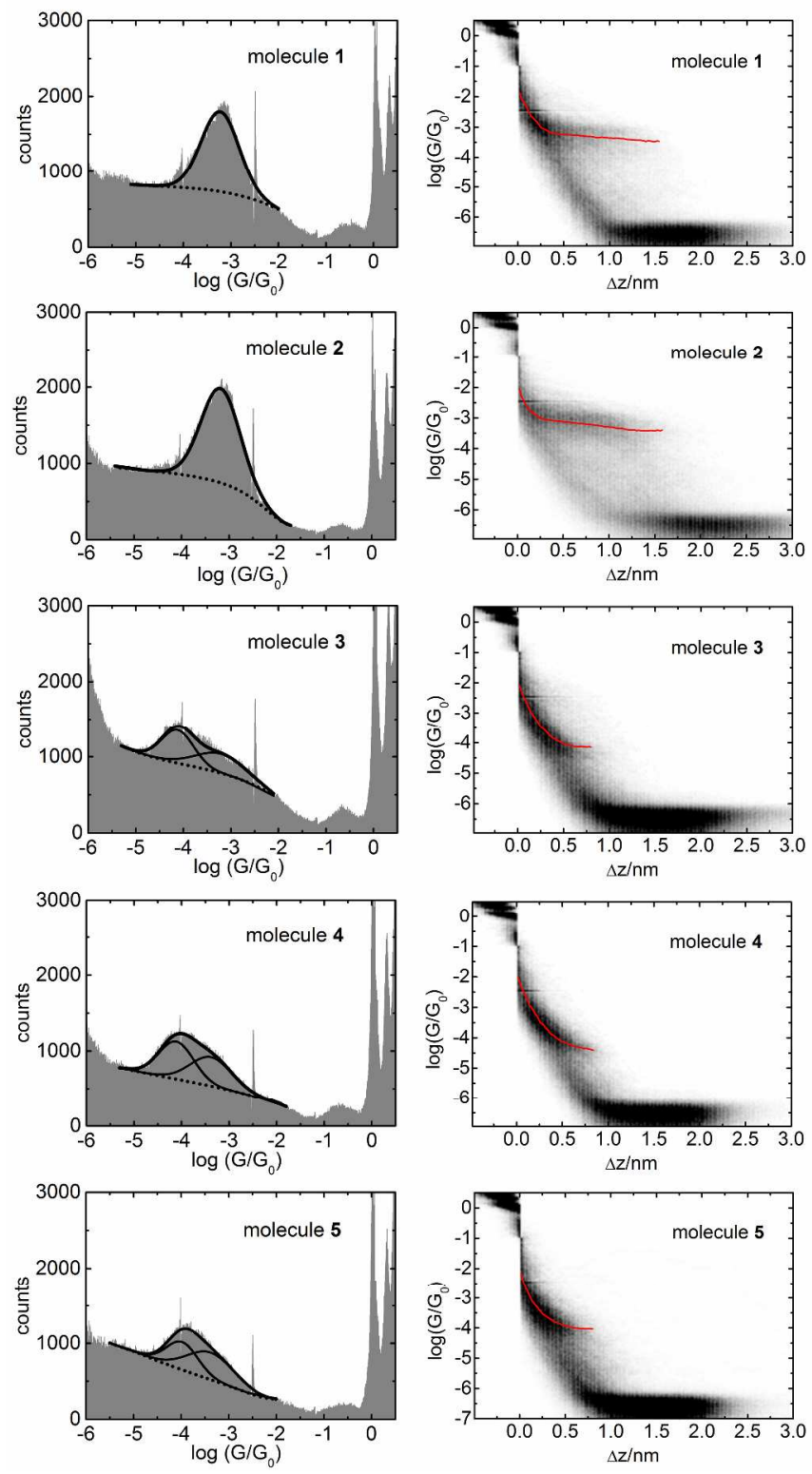

Conductance histograms

$360 \times 657 \mathrm{~mm}(300 \times 300$ DPI $)$ 

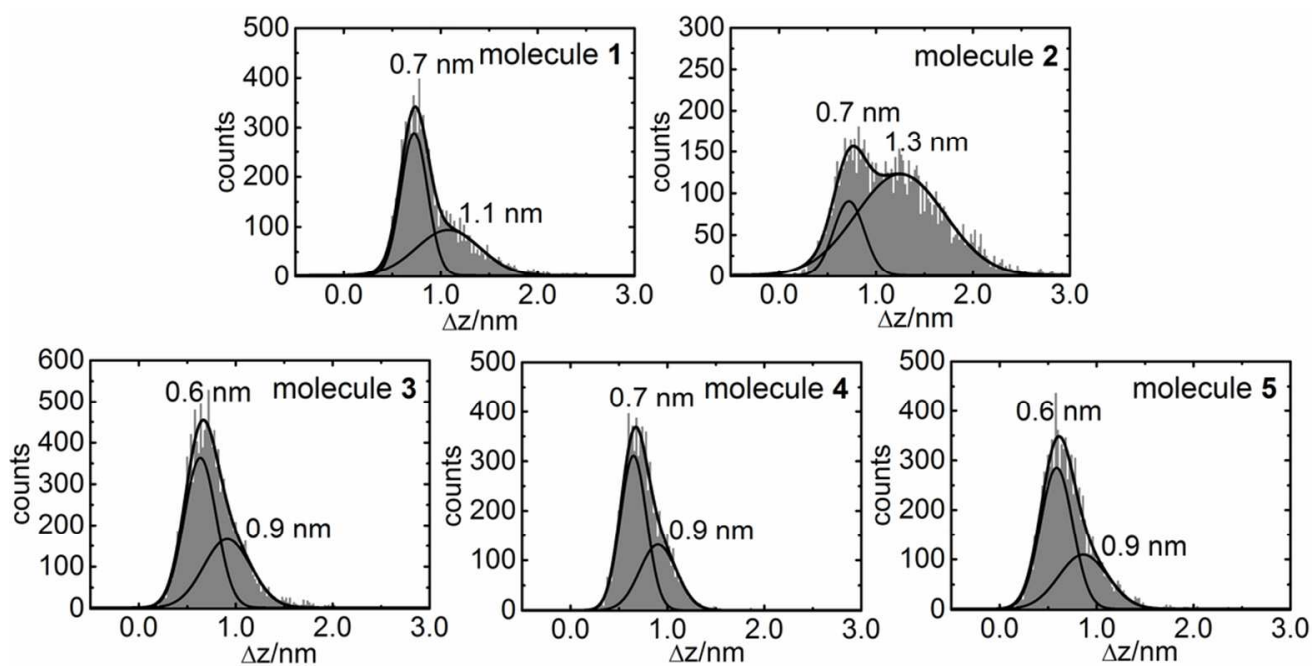

Length histogram

$99 \times 50 \mathrm{~mm}(300 \times 300$ DPI $)$ 


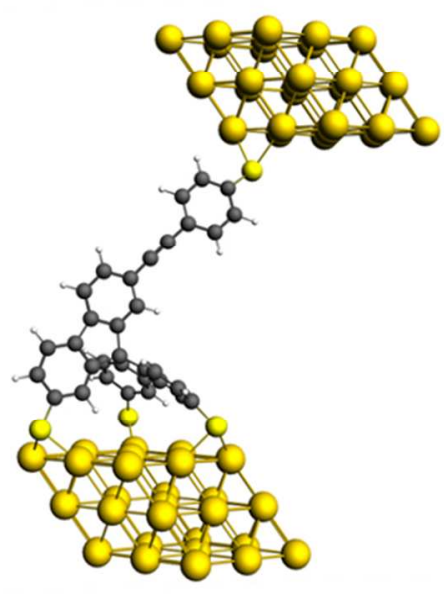

1a

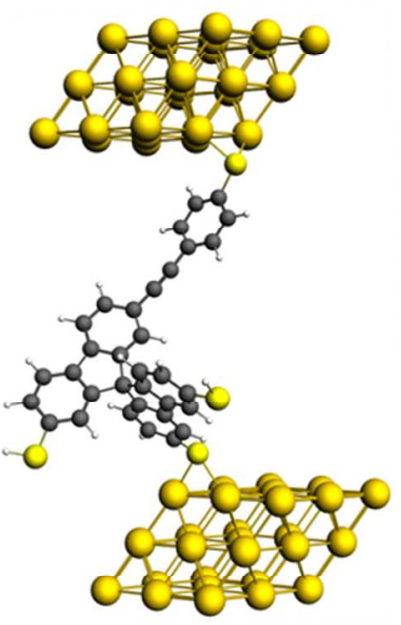

1c

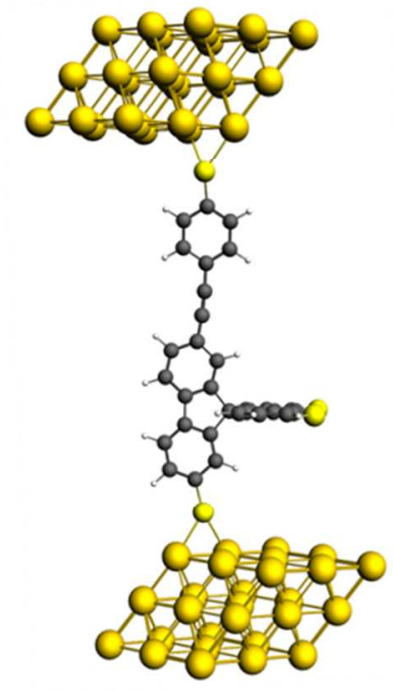

1b

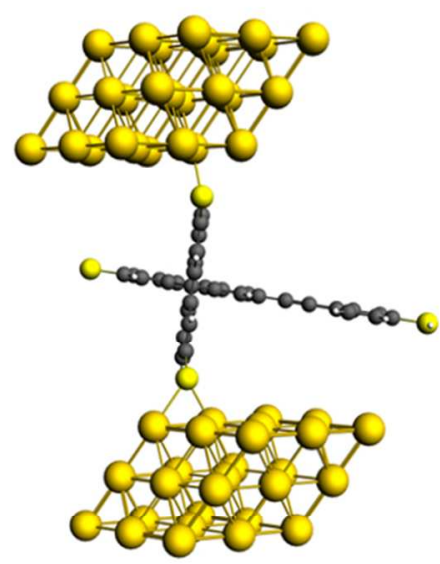

1d

Junction configurations

$182 \times 291 \mathrm{~mm}(96 \times 96$ DPI) 


1
2
3
4
5
6
7
8
9
10
11
12
13
14
15
16
17
18
19
20
21
22
23
24
25
26
27
28
29
30
31
32
33
34
35
36
37
38
39
40
41
42
43
44
45
46
47
48
49
50
51
52
53
54
55
56
57
58
60

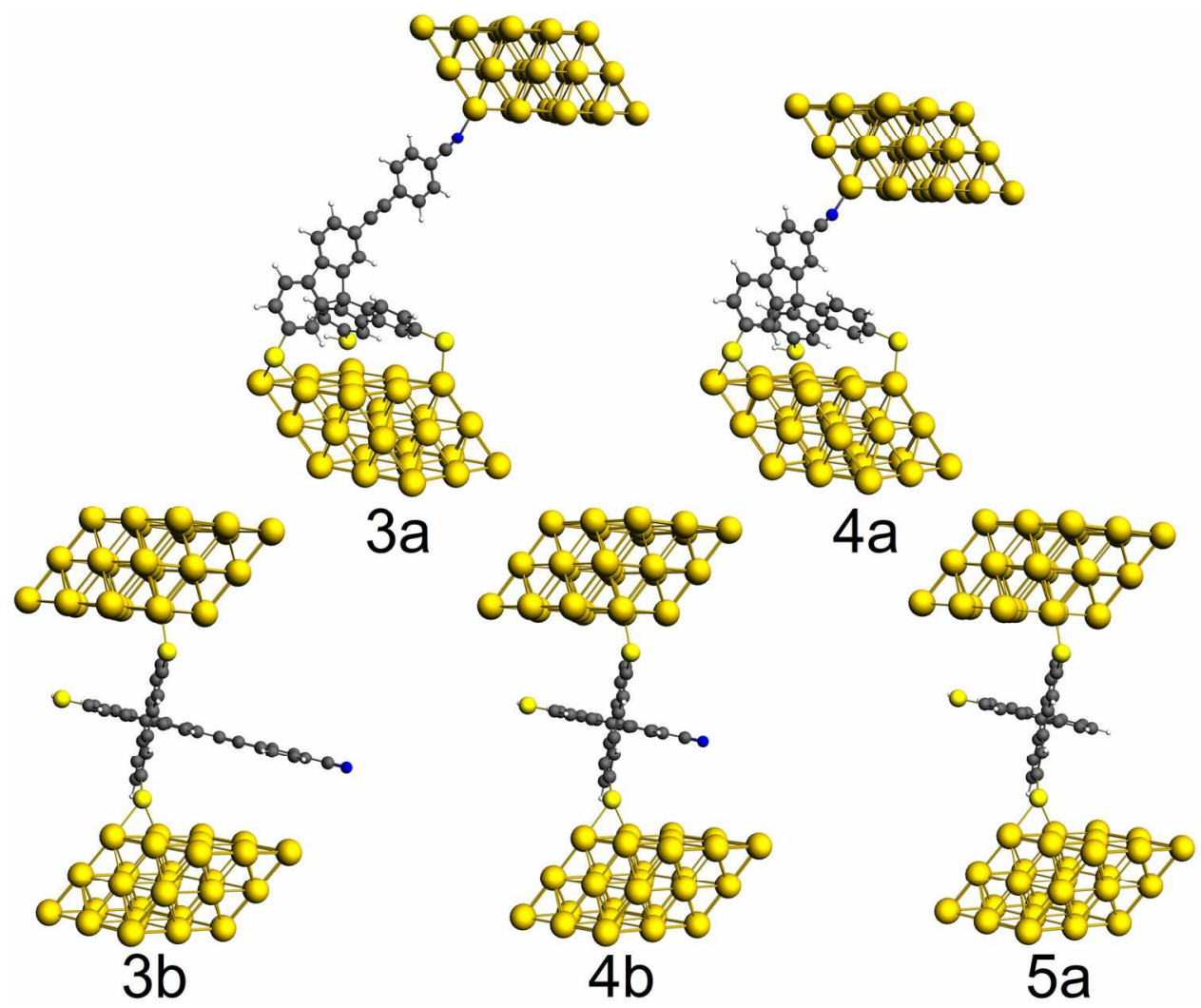

Junction configurations

$160 \times 128 \mathrm{~mm}(300 \times 300 \mathrm{DPI})$ 


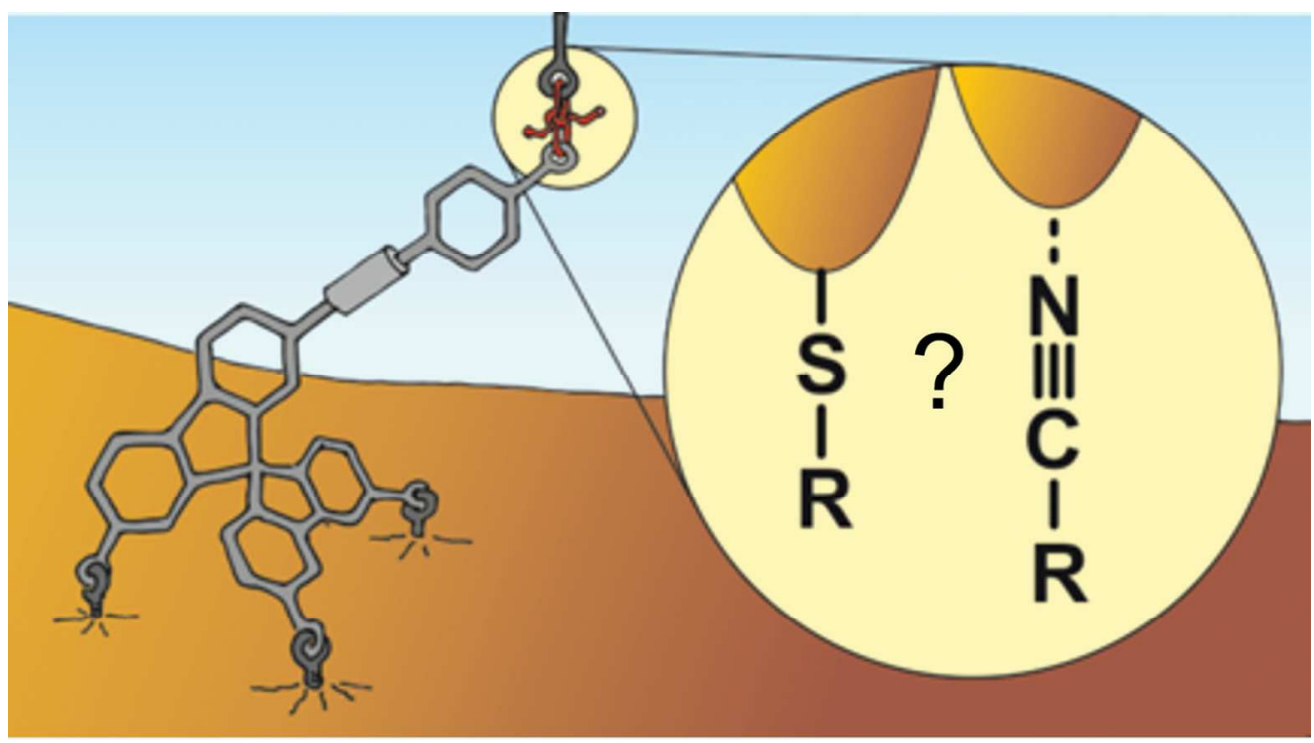

For Table of Contents only

$52 \times 29 \mathrm{~mm}(600 \times 600 \mathrm{DPI})$ 